\section{Transfer Fiyatlandırması Yoluyla Örtülü Kazanç Dağıtımında İlişkili Kişi Kavramının 6728 Sayılı Kanun Kapsamında Değerlendirilmesi}

\author{
Döndü KARA \\ Sakarya Üniversitesi, Sosyal Bilimler Enstitüsü \\ Muhasebe ve Finansman Doktora Öğrencisi \\ donduateskara@hotmail.com
}

\section{Prof. Dr. Ahmet Vecdi CAN}

Sakarya Üniversitesi, İşletme Fakültesi

İşletme Bölümü

acan@sakarya.edu.tr
Transfer Fiyatlandırması Yoluyla Örtülü

Kazanç

Dağıtımında İlişkili

Kişi Kavramının

6728 Sayıl1 Kanun

Kapsaminda

Değerlendirilmesi

\begin{abstract}
ÖZET
09.08.2016 Tarihli 29796 Sayılı Resmi Gazete'de yayımlanan, 6728 Sayılı Yatırım Ortamının İyileştirilmesi Amacıyla Bazı Kanunlarda Değişiklik Yapılmasına Dair Kanun'un 59. maddesi ile, 5520 Sayılı Kurumlar Vergisi Kanunu'nun, "transfer fiyatlandırması yoluyla örtülü kazanç dă̆̆tımı" başlıklı 13. maddesinde birtakım değişiklikler yapılmıştır.

$\mathrm{Bu}$ çalışmada, transfer fiyatlandırması yoluyla örtülü kazanç dağıtımının unsurlarından olan "ilişkili kişi" kavramına ilişkin olarak mevcut yasal düzenlemeler ortaya konulduktan sonra, bu kavramla ilgili olarak akademik literatürde de inceleme ve eleştiri konusu yapılan eksik yönlerin, 6728 Sayılı Kanun'un getirdiği değişiklikler sonrasındaki durumu ele alınmıştır.

6728 Sayılı Kanun'la yapılan düzenleme uyarınca, ilişkili kişinin belirlenmesinde en az \%10 oranında ortaklık, oy veya kâr payı hakkının bulunması şartının getirilmesinin, olumlu bir düzenleme olduğu kanaatine varılmıştır.
\end{abstract}

Anahtar Kelimeler: Transfer Fiyatlandırması, Örtülü Kazanç Dağıtımı, İlişkili Kişi

Jel Sınıflandırması: M40, M41, M48 


\section{Transfer}

Fiyatlandırması

Yoluyla Örtülü

Kazanç

Dağıtımında İlişkil

Kişi Kavramının

6728 Sayılı Kanun

Kapsaminda

Değerlendirilmesi

14

\section{The Evaluation of Consept of Related Part At Distribution of Concealed Revenue Via Tranfer Pricing Within the Content of 6728 Numbered Law ABSTRACT}

Some changes have been made to the Law Amending Changes in Some Laws for the Improvement of the Investment Enviroment which has numbered 6728, with article 59 of the Law, which has serial numbers one published in official journal dated August 9th, 2016 and numbered 29796 , "distribution of concealed revenue via tranfer pricing" titled 13th article of 5520 numbered Corporation Tax Law. In this study, first exiting legal regulations on "related part" which is on of the factors of disribution of concealed revenue via transfer pricing presented, and then deficient aspects of this concept, which have been studies and criticized in academic literature, have been discussed after the changes that came with 6728 numbered Law. It's believed that it's a good regulation that the condition being set with the changes of 6728 numbered Law on identifying the related part share at least $10 \%$ partnership, having the right to vote or receive dividend.

Keywords: Transfer Pricing, Embedded Revenue Allocation, Related Part

Jel Classification: M40, M41, M48

\section{GİRiş}

Bilindiği üzere, 5422 Sayılı Kurumlar Vergisi Kanunu'nun 17. maddesinde düzenlenmiş olan "örtülü kazanç" müessesesi, uluslararası gelişmeler ile Ekonomik İşbirliği ve Kalkınma Teşkilatı'nın (OECD) yaklaşımı da esas alınarak, 13.06.2006 tarihinde kabul edilen, 21.06.2006 Tarih ve 26205 Sayılı Resmi Gazete' de yayımlanarak yürürlüğe giren 5520 Sayılı Kurumlar Vergisi Kanunu ile geçerliliğini yitirmiştir. Birçok terim ve kavramın revize edilerek yeniden tanımlandığı 5520 Sayılı Kurumlar Vergisi Kanunu'nda, “transfer fiyatlandırması” müessesesi de, 13. maddede "transfer fiyatlandırması yoluyla örtülü kazanç dağıtımı" başlığ altında, 01.01.2007 tarihinden itibaren geçerli olmak üzere, yeniden tesis edilmiştir.

Böylelikle, 5520 Sayılı Kurumlar Vergisi Kanunu'nun “transfer fiyatlandırması yoluyla örtülü kazanç dağıtımı" başlıklı 13. maddesinde ve 193 Sayılı Gelir Vergisi Kanunu'nun "indirilemeyecek giderler” başlıklı 
41/5. maddesi, Türk Vergi Sistemi'nde transfer fiyatlandırması yoluyla örtülü kazanç dağıtımı müessesesinin yasal temelini teşkil etmektedir. Maliye Bakanlığı ise, bu düzenlemelerin uygulamasını göstermek amacıyla, 18.11.2007 tarihli 26704 Sayılı Resmi Gazete'de yayımlanan “1 Seri Nolu Transfer Fiyatlandırması Yoluyla Örtülü Kazanç Dağıtımı Hakkında Genel Tebliğ"'i hazırlamıştır. Bir diğer düzenleme ise, Bakanlar Kurulu'nun, KVK md.13 ve GVK md. 41/5 hükümlerinin uygulanmasına ilişkin usulleri ortaya koymak amacıyla, 06.12.2007 Tarihli 26722 Sayılı Resmi Gazete'de yayımlanan 2007/12888 Nolu “Transfer Fiyatlandırması Yoluyla Örtülü Kazanç Dağıtımı Hakkında Karar"1dır.

Daha sonra, 5520 Sayılı Kurumlar Vergisi Kanunu'nun 13. maddesinin uygulamasına ilişkin olarak, transfer fiyatlandırması yoluyla örtülü kazanç dağıtımına dair bazı açıklamaların yapılmasına duyulan ihtiyaç dolayısıyla, 22.04.2008 Tarihli 26855 Sayılı Resmi Gazete'de “2 Seri Nolu Transfer Fiyatlandırması Yoluyla Örtülü Kazanç Dağıtımı Hakkında Genel Tebliğ" yayımlanmıştır. Ayrıca, 16 Mart 2016 tarihinde, 1 Seri Nolu Tebliğ'in ilgili bölümlerinde yapılan değişikliklerin konu edildiği, "3 Seri Nolu Transfer Fiyatlandırması Yoluyla Örtülü Kazanç Dağıtımı Hakkında Genel Tebliğ" taslağı yayımlanmıştır.

Son olarak, 09.08.2016 Tarihli 29796 Sayılı Resmi Gazete'de yayımlanan, 6728 Sayılı Yatırım Ortamının İyileştirilmesi Amacıyla Bazı Kanunlarda Değiş̧iklik Yapılmasına Dair Kanun'un 59. maddesi ile, 5520 Sayılı Kurumlar Vergisi Kanunu'nun 13. maddesinde bir takım değişikliklere gidilmiş ve uygulamadaki bazı belirsizlikler netlik kazanmıştır.

Özellikle, 1 Seri Nolu Tebliğ'in yayınlanmasıyla birlikte, transfer fiyatlandırması yoluyla örtülü kazanç dağıtımı konusu ile ilgili bilimsel ve akademik çalışmalar yayınlanmaya başlamıştır. Yapılan çalışmalarda, transfer fiyatlandırması yoluyla örtülü kazanç dağıtımı konusu; transfer fiyatlandırması kapsamında düzeltme işlemleri, dönem sonu işlemler, hazine zararı, kar payı dağıtımı, ilişkili kişiler ve emsallere uygunluk ilkesi, emsale uygun fiyatın belirlenmesinde kullanılan yöntemler, peşin fiyat anlaşmaları ve transfer fiyatlandırması raporu gibi hususlar kapsamında değerlendirilmiştir.

$\mathrm{Bu}$ çalışmada, transfer fiyatlandırması yoluyla örtülü kazanç dağıtımı müessesinde ilişkili kişi kavramı, 5520 Sayılı Kurumlar Vergisi Kanunu, 193 Sayılı Gelir Vergisi Kanunu, Maliye Bakanlığı tarafından yayımlanan Transfer Fiyatlandırması Yoluyla Örtülü Kazanç Dağıtımı Hakkında 1 Seri Nolu Tebliğ, 2 Seri Nolu Tebliğ, 3 Seri Nolu Tebliğ Taslağ 1 
Transfer

Fiyatlandırması

Yoluyla Örtülü

Kazanç

Dağıtımında İlişkil

Kişi Kavramının

6728 Sayılı Kanun

Kapsaminda

Değerlendirilmesi

16 ve son olarak 6728 Sayılı Torba Kanun çerçevesinde değerlendirilecektir. $\mathrm{Bu}$ bağlamda, transfer fiyatlandırması yoluyla örtülü kazanç dağıtımı hakkında, tam ve dar mükellef gerçek kişi ve kurumları bilgilendirmek amaciyla,

- Transfer fiyatlandırması kavramı,

- Örtülü kazanç kavramı,

- Transfer fiyatlandırması yoluyla örtülü kazanç dağıtımı,

- 5520 Sayılı Kurumlar Vergisi Kanunu açısından transfer fiyatlandırması uygulamasının kapsamına giren ilişkili kişiler,

- 193 Sayılı Gelir Vergisi Kanunu açısından, transfer fiyatlandırması uygulamasının kapsamına giren ilişkili kişiler, hakkında açıklamalar yapılacaktır.

\section{KAVRAMSAL ÇERÇEVE}

Çalışmanın bu bölümünde transfer fiyatlandırması, örtülü kazanç dağıtımı ve transfer fiyatlandırması yoluyla örtülü kazanç dağıtımı kavramları açılanmış, ayrıca mevcut yasal düzenlemeler ve son kanun değişiklikleri kapsamında transfer fiyatlandırması yoluyla örtülü kazanç dağıtımında ilişkili kişi müessesesi anlatılmıştır.

\subsection{Transfer Fiyatlandırması Yoluyla Örtülü Kazanç Dağıtımı}

Bir işletmenin faaliyet kısımları, ülke sınırları içinde ya da dışındaki iştirakleri veya fabrikaları olabileceği gibi, bir fabrikasındaki çeşitli departmanları da olabilmektedir. Bu faaliyet kısımlarının birbirleri ile yaptıkları hammadde, parça, nihai mamul, yatırım malları ve hizmet transferleri, miktar ölçülerinin yanı sıra parasal değerleriyle de izlenirler (Casey, 1985'e atfen, Pazarçeviren, 1987, 35-36). Kısımlar arasında transfer edilen malların parasal değerleri, firmanın benimsediği merkezcil ya da merkezkaç yönetim anlayışına göre farklılık gösterecektir. Fakat, hangi yönetim anlayışı olursa olsun, transfer fiyatı; işletmenin bir kısmından diğer bir kısmına transfer edilen mal ya da hizmetler için yüklenilen bir iç fiyat olarak tanımlanmaktadır (Heitger, Matulich, 1980'e atfen, Pazarçeviren, 1987,36).

İşletmenin bölümleri arasındaki mal veya hizmet alışverişinde oluşan transfer fiyatı, mal ya da hizmeti satan bölüm için bir gelir doğururken; alıcı bölüm için de diğer bölümden alınan mal ya da hizmetin alım maliyetini oluşturur. Böylelikle, mal ya da hizmet alışı ya da satışındaki fiyatlama, işletme bölümlerinin faaliyet karlarını etkileyen bir 
unsur olarak ortaya çıkmaktadır (Horngren vd., 2000'e atfen, Misırlığlu, 2003,177). Bu etkileşim, bölüm yöneticisinin başarısını doğrudan etkilemektedir. Çünkü, alıcı olan bölüm kendi faaliyet karını artırmak için, düşük bedelle alım yapmak isterken, satıcı olan bölüm de, satış bedelini en üst düzeyde gerçekleştirmek isteyecektir (Misırlığlu, 2003,177).

Transfer fiyatlandırması, maksimum kar minimum vergi mantığına dayanarak amaç uygunluğunu ve ideal performansı değerlendirmek için, bağlı kuruluş ya da birimler arasında aktarılan ilk madde, yarı mamul, mamul veya parçaları fiyatlandırma stratejisidir (Borokowsji, 1997'e atfen, Ece, 2016,101; Güney ve Bozkurt, 2010,394). Bu bağlamda transfer fiyatlandırması, bir firmanın gelir-gider veya kar paylaşımı olarak ilişkili olduğu, kar paylaşımı bakımından aynı çıkar birliğine dahil olan ana şirket ya da alt şirketlere ya da, yönetim ve denetim bakımından hakim olduğu ortaklık, iştirak ve şubeleri arasında ticari ve mali faaliyetlerinde kullanılan fiyatların (Saraçoğlu ve Kaya, 2006'ya atfen, Erol, 2013,4), serbest piyasada aynı veya benzer koşullar altında, aynı ya da benzer faaliyetlere taraf bağımsız kişiler arasında karşılaştırılabilecek fiyatlara göre, önemli derecede farklılık göstermesidir (Soydan, 1995'e atfen, Şakar, 2008, 191-192; Elitaş vd., 2009, 24).

Kısacası, transfer fiyatlandırması (transfer pricing), işletmenin ilişki içinde olduğu kişi ya da kurumlar arasında, mal veya hizmet alım ya da satımında uygulanan fiyatı ya da parasal değeri ifade etmektedir. Transfer fiyatlandırması, ilişkili kişiler arasındaki mal veya hizmet alımsatımlarının, iktisadi ve ticari koşullar dikkate alınarak nasıl belirlenmesi gerektiği yönünde temel ilkeleri ortaya koyan bir kavramdır (GİB, 2010,2, Işık, 2005, 23; Consulta,2017, 2).

Örtülü kazanç dağıtımı ise, kurum kazancının vergilendirilmeden kurum dışına aktarılmasını ifade etmektedir (GIB, 2010,2). Kurum kazancı vergilendirildikten sonra, kar dağıtımı yapıldığında ortakların elde ettiği kar paylarından ayrıca gelir vergisi alınması, elde edilen kazanç üzerindeki vergi yükünü artırmaktadır. Bu durumda, kurum kazancının vergilendirildikten sonra, ortaklara kar dağıtımının yapılması yerine, edinilen kazancın bazı hukuki yollar kullanılarak kurumlar vergisi dışında bırakılıp, ortaklar lehine aktarılması halinde örtülü kazanç doğmuş olacaktır. Bu nedenle, örtülü kazanç dağıtımını önlemeye yönelik olarak transfer fiyatlandırması, bir "vergi güvenlik müessesesi" işlevi görmektedir (Şakar, 2008,191).

Buradan hareketle, "transfer fiyatlandırması yoluyla örtülü kazanç dağıtımını", ilişkili kişi ve kurumların, emsallerinden farklı fiyat ya da 
Transfer

Fiyatlandırması

Yoluyla Örtülü

Kazanç

Dağıtımında İlişkil

Kişi Kavramının

6728 Sayılı Kanun

Kapsaminda

Değerlendirilmesi

18 bedelle, kendi aralarında mal veya hizmet alış ya da satış faaliyetlerinde bulunmaları neticesinde, vergi matrahını aşındırmaları ve kurum kazancının vergilendirilmeden ortaklara veya diğer ilişkili kişilere aktarılması şeklinde ifade etmek mümkündür. Bu çerçevede yapılan düzenlemelerin amacı, ilişkili kişilerle mal veya hizmet alışverişinde bulunan gerçek kişi ve kurumların gelirlerinin tam ve doğru olarak beyan edilmesini sağlamak ve transfer fiyatlandırması yoluyla vergi matrahının aşındırılmasına engel olmaktır (GİB, 2010,2; Gümüş, 2007,140; Consulta, 2017,2).

\section{KURUMLAR VERGISİ KANUNU VE GELIR VERGİSI KANUNU ÇERÇEVESINDE TRANSFER FIYATLANDIRMASI YOLUYLA ÖRTÜLÜ KAZANÇ UYGULAMASININ KAPSAMINA GİREN İLIŞKİLI KIŞİLER VE İŞLEMLER}

Küreselleşme ile birlikte artık, çok uluslu firmalar üretim faaliyetlerini global ölçekte planlamaktadırlar. Çok uluslu firmalar, faaliyette bulundukları ülkelerde elde ettikleri karları, ana merkez ülkelere transfer etmekte, faaliyette bulundukları ülkelerin vergi gelirlerini aşındırmakta, böylelikle karlarını maksimize etmekte ya da zararlarını en aza indirmektedirler. Vergi matrahının aşındırılmasına neden olan örtülü kazanç, elde edilen karın çevre ülkelerden merkez ülkeye aktarılmasında kullanılan en önemli araçlardan biri haline gelmiştir. Transfer fiyatlandırması yoluyla örtülü kazanç dağıtımına engel olmak amacıyla, $A B D$ ve OECD ülkelerinde bugüne kadar önemli düzenlemeler yapılmıştır (Gümüş, 2007,140; Çakır, 2009,40). Türkiye'de ise, tam ve dar mükellef gerçek kişi ve kurumların tamamı, transfer fiyatlandırması uygulamasının kapsamına dahil olup; bu gerçek kişi ve kurumların, ilişkili kişilerle gerek ülke içinde gerekse ülke dişındaki faaliyetleri ile ilgili olarak yapacakları mal veya hizmet alış ya da satış işlemleri, transfer fiyatlandırması yoluyla örtülü kazanç dağıtımı çerçevesinde değerlendirilmektedir.

Transfer fiyatlandırması yoluyla örtülü kazanç dağıtımının temelinde yatan "ilişkili kişi"nin, işletme ile yaptığ menfaatin onun ilişkili kişi sıfatına dayanması, yani ilişkili kişi olmanın menfaatin verilmesinde temel belirleyici olmasıdır. Isşletme, ilişkili olmadığ 1 kişilerle yaptığ ilişkili kişi sıfatına dayanan bir menfaat aktarımından söz edilemez (A ğar, 2011'e atfen, Ağar, 2011,195). Transfer fiyatlandırma yoluyla örtülü kazanç dağıtımı ancak, ilişkili kişiye aynı şartlar altında üçüncü bir kişiye verilmeyecek olan bir menfaat sağlandığında meydana gelmektedir. İlişkili kişinin işletme veya ortaktan sağladığı menfaatin temelinde ilişkili kişi 
sıfatı olduğundan, ilişkili olmayan kişilere sağlanan menfaatler transfer fiyatlandırması yoluyla gerçekleşen örtülü kazanç dağıtımı olarak değerlendirilmez (Ağar, 2011,195-196).

TMS-24: İlişkili Taraf Açıklamaları Standardı, transfer fiyatlandırması uygulamalarında öne çıan ve kurumsal örgütlenme modelleriyle yakından ilgili olan "ilişkili kişi” kavramını açıklamaktadır. Türkiye Muhasebe Standartları Kurulu'nun (TMSK), 31 Aralık 2005 Tarih ve 26040 Sayılı Resmi Gazete'de yayımlanan, İlişkili Taraf Açıklamalarına İlişkin Türkiye Muhasebe Standardı (TMS-24) Hakkında 17 Sıra Nolu Tebliğ'in, Türkiye Muhasebe Standardı (TMS-24) İlişkili Taraf Açıklamaları başlıklı Ek'inde, söz konusu standardın amacı, bir işletmenin finansal durumunun ve faaliyet sonuçlarının, ilişkili tarafların mevcudiyeti ile ilişkili taraflarla gerçekleştirilen işlemler ve mevcut bakiyelerden etkilenebileceği olasıllğına dikkat çekmek için, işletmenin finansal tablolarının gerekli açıklamaları içermesini sağlamak olduğu belirtilmiştir. Ayrıca, TMS-24: İlişkili Taraf Açıklamaları Standardı kapsamında yapılan düzenlemede ilişkili kişi kavramına, aşağıda belirtildiği üzere oldukça geniş yer verilmiş, bir kişinin ya da kurumun diğer tarafla "ilişkili kişi" olarak sayılabilmesi için gerekli tanımlar tek tek sayılmıştır. Buna göre, bir tarafın bir işletme ile ilişkili kişi sayılabilmesi için (TMSK, 17 Sıra Nolu Tebliğ, 2005; Ağar, 2011,198-199; Erhan, 2012,116-117):

- Doğrudan veya dolaylı olarak bir veya birden fazla aracı yoluyla işletmeyi denetlemesi, işletme tarafından denetlenmesi veya işletmeyle ortak denetim altında bulunması (ana ortaklıklar, bağlı ortaklıklar ve aynı is dalındaki bağlı ortaklıklar dahil olmak üzere), işletme üzerinde önemli etkisinin olmasını sağlayacak payının olması veya işletme üzerinde ortak denetime sahip olması,

- TMS-28: İştiraklerdeki Yatırımlar Standardı́nda tanımlandığı gibi, işletmenin iştiraki olması,

- İşletmenin ortak girişimci olduğu bir iş ortaklığı olması (TMS-31: İş Ortaklıklarındaki Paylar),

- İşletmenin veya ana ortaklığının kilit yönetici personelinin bir üyesi olması,

- İlk ve bir önceki bentte sayılan kişilerden birinin yakın bir aile üyesi olması,

- Kontrol edilen, ortak kontrol edilen veya önemli etki altında veya bir önceki bentte sayılan kişilerden birinin doğrudan 


\section{Transfer}

Fiyatlandırması

Yoluyla Örtülü

Kazanç

Dağıtımında İlişkil

Kişi Kavramının

6728 Sayılı Kanun

Kapsaminda

Değerlendirilmesi

20 veya dolaylı olarak önemli oy hakkına sahip olduğu bir işletme olması,

- İşletmenin veya işletmeyle ilişkili taraf olan bir işletmenin çalışanlarına işten ayrılma sonrasında sağlanan fayda planları olması gerekmektedir.

Çalışmanın bu bölümünde, transfer fiyatlandırması yoluyla örtülü kazanç dağıtımında ilişkili kişi kavramı, kurumlar vergisi mükellefleri bakımından 5520 Sayılı Kurumlar Vergisi Kanunu ile 6728 Sayılı Yatırım Ortamının İyileştirilmesi Amacıyla Bazı Kanunlarda Değişiklik Yapılmasına Dair Kanun ve gelir vergisi mükellefleri bakımından 193 Sayılı Gelir Vergisi Kanunu kapsamında değerlendirilecektir.

\subsection{Kurumlar Vergisi Kanunu'na Göre İlişkili Kişi ve İşlemler}

Transfer fiyatlandırması yoluyla örtülü kazanç dağıtımı konusuna kurumlar vergisi mükellefleri açısından bakıldığında, uluslararası gelişmeler ve özellikle OECD'nin yasal düzenlemeleri dikkate alınarak, 5520 Sayılı Kurumlar Vergisi Kanunu'nun 13. maddesinde "transfer fiyatlandırması yoluyla örtülü kazanç dağıtımı" başlığı altında aynen şu ifadelerle tesis edildiği görülmektedir (5520 Sayılı Kurumlar Vergisi Kanunu, 2006, Maliye Bakanlığı 1 Seri Nolu Transfer Fiyatlandırması Yoluyla Örtülü Kazanç Dağıtımı Hakkında Genel Tebliğ, 2007, Erol, 213, 54-56):

“Transfer fiyatlandırması yoluyla örtülü kazanç dağıtımı

Madde 13 - (1) Kurumlar, ilişkili kişilerle emsallere uygunluk ilkesine aykırı olarak tespit ettikleri bedel veya fiyat üzerinden mal veya hizmet alım ya da satımında bulunursa, kazanç tamamen veya kısmen transfer fiyatlandırması yoluyla örtülü olarak dağıtılmıss sayılır. Alım, satım, imalat ve inşaat işlemleri, kiralama ve kiraya verme işlemleri, ödünç para alınması ve verilmesi, ikramiye, ücret ve benzeri ödemeleri gerektiren işlemler her hal ve şartta mal veya hizmet alım ya da satımı olarak değerlendirilir.

(2) İlişkili kişi; kurumların kendi ortakları, kurumların veya ortaklarının ilgili bulunduğu gerçek kişi veya kurum ile idaresi, denetimi veya sermayesi bakımından doğrudan veya dolaylı olarak bağlı bulunduğu ya da nüfuzu altında bulundurduğu gerçek kişi veya kurumları ifade eder. Ortakların eşleri, ortakların veya eşlerinin üstsoy ve altsoyu ile üçüncü derece dahil yansoy hısımları ve kayın hısımları da ilişkili kişi sayılır. Kazancın elde edildiği ülke vergi sisteminin, Türk vergi sisteminin yarattı̆̆ vergilendirme kapasitesi ile aynı düzeyde bir vergilendirme imkânı sağlayıp să̆lamadığı ve bilgi değişimi hususunun göz 
önünde bulundurulması suretiyle Bakanlar Kurulunca ilan edilen ülkelerde veya bölgelerde bulunan kişilerle yapılmış tüm işlemler, ilişkili kişilerle yapılmış sayılır.

(3) Emsallere uygunluk ilkesi, ilişkili kişilerle yapılan mal veya hizmet alım ya da satımında uygulanan fiyat veya bedelin, aralarında böyle bir ilişkinin bulunmaması durumunda oluşacak fiyat veya bedele uygun olmasın ifade eder. Emsallere uygunluk ilkesi doğrultusunda tespit edilen fiyat veya bedellere ilişkin hesaplamalara ait kayıt, cetvel ve belgelerin ispat edici kâğıtlar olarak saklanması zorunludur.

(4) Kurumlar, ilişkili kişilerle yaptığı işlemlerde uygulayacă̆ı fiyat veya bedelleri, aşă̆ıdaki yöntemlerden işlemin mahiyetine en uygun olanın kullanarak tespit eder:

a) Karşılaştırılabilir fiyat yöntemi: Bir mükellefin uygulayacă̆ı emsallere uygun satış fiyatının, karşılaştırılabilir mal veya hizmet alım ya da satımında bulunan ve aralarında herhangi bir şekilde ilişki bulunmayan gerçek veya tüzel kişilerin birbirleriyle yaptıkları işlemlerde uygulayacağı piyasa fiyatı ile karşılaştırılarak tespit edilmesini ifade eder.

b) Maliyet artı yöntemi: Emsallere uygun fiyatın, ilgili mal veya hizmet maliyetlerinin makul bir brüt kâr oranı kadar artırılması suretiyle hesaplanmasını ifade eder.

c) Yeniden satış fiyatı yöntemi: Emsallere uygun fiyatın, işlem konusu mal veya hizmetlerin aralarnda herhangi bir şekilde ilişki bulunmayan gerçek veya tüzel kişilere yeniden satılması halinde uygulanacak fiyattan, makul bir brüt satış kârı düşülerek hesaplanmasını ifade eder.

ç) Emsallere uygun fiyata yukarıdaki yöntemlerden herhangi birisi ile ulaşma olană̆ı yoksa mükellef, işlemlerin mahiyetine uygun olarak kendi belirleyeceğ $\mathrm{g}$ diğer yöntemleri kullanabilir.

(5) İlişkili kişilerle yapılan mal veya hizmet alım ya da satımında uygulanacak fiyat veya bedelin tespitine ilişkin yöntemler, mükellefin talebi üzerine Maliye Bakanlı̆̆ $\mathrm{l}$ ile anlaşılarak belirlenebilir. Bu şekilde belirlenen yöntem, üç yılı aşmamak üzere anlaşmada tespit edilen süre ve şartlar dâhilinde kesinlik taşır.

(6) Tamamen veya kısmen transfer fiyatlandırması yoluyla örtülü olarak dağıtılan kazanç, Gelir ve Kurumlar Vergisi kanunlarının uygulamasında, bu maddedeki şartların gerçekleştiği hesap döneminin son günü itibarıyla dă̆ıtılmış kâr payı veya dar mükellefler için ana merkeze aktarılan tutar sayılır. Daha önce yapulan vergilendirme işlemleri, taraf olan mükellefler nezdinde buna göre düzeltilir. Şu kadar ki, bu düzeltmenin yapılması için örtülü kazanç dağıtan kurum adına tarh edilen vergilerin kesinleşmiş ve ödenmiş olması şarttır. 
Transfer

Fiyatlandırması

Yoluyla Örtülü

Kazanç

Dağıtımında İlişkil

Kişi Kavramının

6728 Sayılı Kanun

Kapsaminda

Değerlendirilmesi

22
(7) Transfer fiyatlandırması ile ilgili usuller Bakanlar Kurulunca belirlenir."

Burada "kurum" terimi, sermaye şirketleri, kooperatifler, iktisadi kamu kuruluşları, dernek veya vakıflar ile bunlara ait iktisadi işletmeleri ve iş ortaklıklarını ifade etmektedir (Consulta, 3). Yine, KVK'nın 13. maddesinde geçen "gerçek kişi" kavramı, Gelir Vergisi Kanunu'nun uygulanmasında gerçek kişi olarak kabul edilip, vergiye tabi tutulan şahıslar ile şahıs şirketleri ya da adi ortaklıkları kapsamaktadır (Tekin, Kartaloğlu, 2007,95; Akdoğan, 2007; Güler, 2006; Bulut, 2012,112). 1 Seri Nolu Transfer Fiyatlandırması Yoluyla Örtülü Kazanç Dağıtımı Hakkında Genel Tebliğ ve KVK'nın 13/2. maddesinde açıç̧a belirtildiği üzere, bir kurum açısından "ilişkili kişi" kavramı ise (Erol, 2013,38);

- Kurumların kendi ortaklarını,

- Kurumların veya ortaklarının ilgili bulunduğu gerçek kişi veya kurumları,

- Kurumların veya ortaklarının idaresi, denetimi veya sermayesi bakımından doğrudan veya dolaylı olarak bağlı bulunduğu ya da nüfuzu altında bulundurduğu gerçek kişi veya kurumları,

- Ortakların eşlerini,

- Ortakların veya eşlerinin üstsoy ve altsoyu ile üçüncü derece dahil yansoy hisımlarını ve kayın hisımlarını ifade etmektedir.

Kanun'da tek tek sayılan ilişkili kişi kavramına 1 Seri Nolu Tebliğ çerçevesinde bakıldığında, kurumların kendi ortaklarından kastedilenin, kurumların doğrudan veya dolaylı olarak sermaye payına sahip gerçek kişi veya kurumlar olduğu açıktır. Kurumun ilgili bulunduğu gerçek kişi ifadesinden, kendi ortağı olan gerçek kişiler dışında kalan, kurumların ortağı olduğu şahıs şirketlerinin diğer gerçek kişi ortakları ile kurum çalışanları gibi şahıslar anlaşılmaktadır. Kurum çalışanlarının söz konusu kurum ile ilişkilerinin sadece işveren hizmet erbabı ilişkisi içinde bulunması durumunda ilgili kurum ile kurum çalışanı, yapılan ücret ödemeleri bakımından ilişkili kişi kapsamında değerlendirilmeyecektir. Fakat, kurum ile çalışanları arasında yukarıda belirtilen istihdam ilişkisi dışındaki işlemler, ilişkili kişilerle yapılan işlem kapsamında değerlendirilecektir.

Kurumun ilgili bulunduğu kurum ise, kendi ortağı dişında, kurumun kendisinin ortaklığının bulunduğu bir başka kurumu yani 
iştiraklerini ifade etmektedir. Bir kurum diğer bir kuruma ortak ise, iki kurum ilişkili sayılacak, ortak olduğu kurum üzerinden başka bir kuruma ortak ise dolaylı olarak ilişkili olduğu kabul edilecektir. Diğer bir ifadeyle, kurumların doğrudan veya dolaylı olarak iştirak ettiği diğer kurumlar ve şahıs şirketleri ilişkili kişi kapsamında değerlendirilecektir. Kurum ortağının ilgili bulunduğu kurum ise, kurum ortağının başka bir kurum ile olan ortaklık ilişkisini ifade etmektedir. Ayrıca kurum ortağının ortak olduğu şahıs şirketlerinin diğer kurum ortakları ilişkili kişi sayılacaktır. Diğer bir ifadeyle, kurum ortaklarının doğrudan veya dolaylı olarak ortak olduğu kurumlar ve şahıs şirketleri ile söz konusu kurum ve şahıs şirketlerinin diğer kurum ortakları ilişkili kişi sayılacaktır. Örneğin; bir kurumun kendi ortağı tüzel kişinin iştiraki olan başka bir tüzel kişi ile yaptığı mal veya hizmet alım ya da satım işlemleri ilişkili kişilerle yapılmış sayılacaktır.

Kurumun veya ortaklarının idaresi bakımından doğrudan veya dolaylı olarak bağlı bulunduğu gerçek kişiler; ortaklık ilişkisi olmaksızın kurumun kararlarında doğrudan veya dolaylı olarak etkisi bulunabilecek kurumun yönetim kurulu başkan ve üyeleri, genel müdürü, üst düzey müdürleri, aynı düzeydeki yüksek memurları gibi şahısları ifade etmektedir. Ayrıca, ortaklık ilişkisi olmaksızın kurumun kararlarında doğrudan veya dolaylı olarak etkide bulunabilecek herhangi bir gerçek kişi veya kurum ilişkili kişi sayılacaktır. Kurumun veya ortaklarının denetimi bakımından doğrudan veya dolaylı olarak bağlı bulunduğu gerçek kişi veya kurumlar ifadesinden, ortaklık ilişkisi olmaksızın kurumun kararlarında doğrudan veya dolaylı olarak etkisi bulunabilecek kurumun denetçileri gibi gerçek ve tüzel kişiler anlaşılmaktadır. Örneğin, bir limited şirket denetçisinin eşinin ortak olduğu diğer şirketin limited şirket ile yaptığı mal veya hizmet alım ya da satım işlemleri, kurumun denetim bakımından bağlı bulunduğu ilişkili kişilerle yapılan işlemleri ifade etmektedir.

Ayrıca Tebliğ'e göre, kurumun ortaklarının eşleri, ortakların veya eşlerinin anne, baba, büyükanne ve büyükbabaları, çocukları ve torunları ile üçüncü derece dahil yansoy hısımları (ortak bir kökten gelen kişiler) ve kayın hısımları (eşlerden biri ile diğer eşin kan hısımları) ilişkili kişi sayilacaktır.

5520 Sayılı Kurumlar Vergisi Kanunu'nun 13/1. maddesi gereğince, kurumların ilişkili kişiler ile emsallere uygunluk ilkesine aykırı surette bedel veya fiyat üzerinden mal ya da hizmet alış ve/veya satış faaliyetinde bulunmaları dolayısıyla elde edilecek kazanç, tamamen veya kısmen transfer fiyatlandırması yoluyla örtülü olarak dağıtılmış kabul 
Transfer

Fiyatlandırması

Yoluyla Örtülü

Kazanç

Dağıtımında İlişkil

Kişi Kavramının

6728 Sayılı Kanun

Kapsaminda

Değerlendirilmesi

24

edilmektedir. Bu kapsamda, alım, satım, imalat ve inşaat işlemleri, kiralama faaliyetleri, kiraya verme işlemleri, ödünç para alınması veya verilmesi, ikramiye, ücret ve benzeri ödemeleri gerektiren işlemler, mal ve hizmet alım ya da satımı olarak değerlendirilmektedir. Buradan hareketle, kurumların ilişkili kişilerle emsallere uygunluk ilkesine göre tespit ettikleri fiyat ya da bedel üzerinden mal ya da hizmet alışverişi yapmaları halinde, transfer fiyatlandırması yoluyla örtülü kazanç dağıtımı gerçekleşmemiş olacaktır. Burada elde edilen kazancın kısmen ya da tamamen örtülü kazanç olarak değerlendirilebilmesi için, ilişkili kişilerle yapılmış olması ve emsallere uygunluk ilkesine aykırı davranılmış olması gerekmektedir (GİB, 2010,2).

Ayrıca, kurumlar vergisi mükellefleri yönünden bağlayıcı bir diğer bir husus ise, KVK'nın "kabul edilmeyen indirimler" başlıklı, 11/1-c maddesidir:

"Kabul edilmeyen indirimler

Madde 11-1: Kurum kazancının tespitinde aşă̆ıdaki indirimlerin yapılması kabul edilemez:

c) Transfer fiyatlandırması yoluyla örtülü olarak dă̆̆ttlan kazançlar."

Zira, yukarıda ilgili maddede belirtildiği üzere, transfer fiyatlandırması yoluyla örtülü olarak dağıtılan kazançların, kurum kazancının tespitinde, kanunen kabul edilmeyen gider mahiyetinde olduğu ve bu nedenle indirim konusu yapılmasının mümkün olmadı̆̆ 1 açıktır. (Şakar, 2008, 192).

22.04.2008 Tarih ve 26855 Sayılı Resmi Gazete'de yayımlanan, Maliye Bakanlığı'nın 2 Nolu Transfer Fiyatlandırması Yoluyla Örtülü Kazanç Dağıtımı Hakkında Genel Tebliğ ile, KVK'nın 13. maddesinin uygulamasına açılık getirmek amacıyla, 1 Seri Nolu Tebliğ'in "3.1.3Kurumun veya Ortaklarının İdaresi, Denetimi veya Sermayesi Bakımından Doğrudan veya Dolaylı Olarak Bağlı Bulunduğu ya da Nüfuzu Altında Bulundurduğu Gerçek Kişi veya Kurumlar" başlıklı bölümünün yedinci paragrafından sonra gelmek üzere aşağıdaki paragraf eklenmiştir:

Örneğin; Almanya'da bulunan (A) şirketi Türkiye'de yerleşik (B) şirketine motorlu araç ve yedek parça satmakta olup (B) şirketi söz konusu ürünlerin Türkiye'ye ithali ile yurt içine satış hakkına sahip bulunmaktadır. (A) şirketi ile Türkiye pazarında dağıtıcı (distribütör) olarak faaliyette bulunan (B) şirketi ilişkili kişi kapsamında değerlendirilecektir. Yurt dışında bulunan şirketin Türkiye pazarında bir veya birden fazla dağıtıcı ile alım-satım faaliyetinde bulunması durumu değiştirmeyecektir. Dolayısıyla aralarında ortaklık ilişkisi bulunup 
bulunmadığına bakılmaksızın, yurt dışında bulunan bir kurum ile Türkiye'de dağıtıcı olarak faaliyette bulunan kurum ilişkili kişi kapsamında değerlendirilecektir. Öte yandan (B) şirketinin, (A) şirketinden aldığı motorlu araç ve yedek parça satışını Türkiye'de yirmibir ilde bulunan bayileri aracılı̆̆ıyla gerçekleştirmesi durumunda, (B) şirketi ile bayileri, bayiliğin konusunu oluşturan işlemler bakımından ilişkili kişi kapsamında değerlendirilmeyecektir.

KVK'nın 13. maddesinde, 09.08.2016 Tarihli 29796 Sayılı Resmi Gazete'de yayımlanan, 6728 Sayılı Yatırım Ortamının İyileştirilmesi Amacıyla Bazı Kanunlarda Değişiklik Yapılmasına Dair Kanun'un 59. maddesi doğrultusunda; ilişkili kişi, işlemsel kar yöntemleri, İdare ile yapılacak anlaşmalar, örtülü kazanç nedeniyle tahakkuk ettirilmemiş ya da eksik tahakkuk ettirilmiş vergiler için vergi ziyaı cezası uygulanacağına dair bir takım değişikliklere gidilmiştir. Bu kapsamda, 6728 Sayılı Kanun'un 59. maddesinde yer alan hükümler şu şekildedir:

“KVK'nın 13. maddesinin:

a) İkinci fikrasına "İlişkinin doğrudan veya dolayl olarak ortaklık kanalıyla oluştuğu durumların örtülü kazanç dağıtımı kapsamında sayılması için en az \%10 oranında ortaklık, oy veya kâr payı hakkının olması şartı aranır. Ortaklık ilişkisi olmadan doğrudan veya dolaylı olarak en az \%10 oranında oy veya kâr payı hakkının olduğu durumlarda da taraflar ilişkili kişi sayılır. İlişkili kişiler açısından bu oranlar topluca dikkate alınır." cümleleri eklenmiştir.

b) Dördüncü fikrasının (ç) bendi aşă̆ıdaki şekilde değgiştirilmiş ve bu bentten sonra gelmek üzere (d) bendi eklenmiştir.

"ç) Isslemsel kâr yöntemleri: Emsallere uygun fiyat veya bedelin tespitinde, iliş̧ili kişiler arasındaki işlemden doğan kârn esas alan yöntemleri ifade eder. Bu yöntemler, işleme dayalı net kâr marjı yöntemi ve kâr bölüşüm yöntemidir. İşleme dayalı net kâr marjı yöntemi, mükellefin kontrol altındaki bir işlemden; maliyetler, satışlar veya varlıklar gibi ilgili ve uygun bir temele dayanarak tespit ettiği net kâr marjının incelenmesi esasına dayanır. Kâr bölüşüm yöntemi, ilişkili kişilerin bir veya daha fazla sayıdaki kontrol altındaki işlemlere ilişkin toplam faaliyet kârı ya da zararının, üstlendikleri işlevler ve yüklendikleri riskler nispetinde ilişkili kişiler arasında emsallere uygun olarak bölüştürülmesi esasına dayanır."

“d) Emsallere uygun fiyata yukarıdaki yöntemlerden herhangi birisi ile ulaşma olană̆̆ yoksa mükellef, işlemin niteliğine uygun olarak kendi belirleyeceğgi bir yöntemi de kullanabilir."

c) Beşinci fikrasına "Mükellef ve Bakanlık, belirlenen yöntemin zamanaşımına uğramamış geçmiş vergilendirme dönemlerine de tatbik edilmesini, Vergi Usul Kanununun pişmanlık ve ıslah hükümlerinin uygulanmasının 
Transfer

Fiyatlandırması

Yoluyla Örtülü

Kazanç

Dağıtımında İlişkil

Kişi Kavramının

6728 Sayılı Kanun

Kapsaminda

Değerlendirilmesi

26 mümkün olması ile anlaşma koşullarının bu dönemlerde de geçerli olması hâlinde, anlaşma kapsamma almak suretiyle sağlayabilir. Bu durumda, imzalanan anlaşma söz konusu hükümlerde yer alan haber verme dilekçesi yerine geçer, beyan ve ödeme işlemleri buna göre tekemmül ettirilir. Anlaşmanın geçmiş vergilendirme dönemlerine uygulanması sebebiyle daha önceden ödenen vergiler ret ve iade edilmez." cümleleri eklenmiştir.

ç) Yedinci fikrasından sonra gelmek üzere aşağıdaki fikra eklenmiş ve mevcut sekizinci fikra buna göre teselsül ettirilmiştir.

“(8) Transfer fiyatlandırmasına ilişkin belgelendirme yükümlülüklerinin tam ve zamanında yerine getirilmiş olması kaydıyla, örtülü olarak dă̆ıtılan kazanç nedeniyle zamanında tahakkuk ettirilmemiş veya eksik tahakkuk ettirilmiş vergiler için vergiziyar cezası (Vergi Usul Kanununun 359 uncu maddesinde yazll fiillerle vergiziyanna sebebiyet verilmesi hali hariç) \%50 indirimli olarak uygulanır."

d) Mevcut sekizinci fikrası aşağıdaki şekilde değiştirilmiştir.

“(9) Bakanlar Kurulu; ikinci fikrada yer alan oranları, gerçek kişiler, kurumlar, doğrudan veya dolaylı ortaklar itibarıla ya da ortaklık payının edinim şekline göre topluca veya ayr ayr \%1'e kadar indirmeye, \%25'e kadar çıkarmaya, oran şartını kaldırmaya; beşinci fikrada yer alan süreyi beş yıla kadar artırmaya, belgelendirme yükümlülükleri ve bu yükümlülükler kapsamına, uluslararası anlaşmalar doğrultusunda, yurt dişında yer alan ilişkili kişilerin faaliyetlerine ilişkin bilgilerin dâhil edilmesi zorunluluğu getirmeye; bu bilgilerin uluslararası anlaşmalar çerçevesinde diğger ülkelerle karşılıklı olarak paylaşılmasına ilişkin usullerle transfer fiyatlandırması ile ilgili diğer usul ve esaslarn belirlemeye yetkilidir."

Transfer fiyatlandırması yoluyla örtülü kazanç dağıtımı müessesesine yön veren gerek 5520 Sayılı Kanun'un 13. maddesinde gerek Gelir İdaresi Başkanlığ 1 tarafından hazırlanan Rehber'de gerekse 1 Seri Nolu Tebliğ'de, ortakların doğrudan ya da dolaylı ortak oldukları kurumlarla ve bu kurumların kendi aralarındaki ilişki, "ilişkili kişi”" olarak nitelendirilmiştir. Bu ilişkilerde, herhangi bir sermaye tutarı veya kar payı oranı belirtilmemiştir. Örtülü sermaye kullanımına ilişkin düzenlemede, ortakla ilişkili kişi tanımında "ortağın doğrudan veya dolaylı olarak en az \%10 oranında ortağı olduğu ya da en az bu oranda oy veya kar payı hakkına sahip olduğu bir kurumu" ifade ettiği halde; transfer fiyatlandırmasına ilişkin düzenlemede, $\% 10$ ya da başka bir orana, oy veya kar payı hakkına sahip olma şartına ya da bir sermaye tutarına yer verilmemiştir. Kurumların ya da ortaklarının ilgili bulunduğu gerçek kişi veya kurum ile idaresi, denetimi veya sermayesi bakımından doğrudan ya 
da dolaylı olarak bağlı bulunduğu veya nüfuzu altında bulundurduğu gerçek kişi ya da kurumlar, ilişkili kişi olarak değerlendirilmiştir.

İşte, uygulamada ciddi sorunlara yol açan bu belirsizlik, 6728 Sayılı Torba Kanun'un 59. maddesiyle Kurumlar Vergisi Kanunu'nun 13/2. maddesinde değişiklikler yapılmasıyla ortadan kaldırılmıştır. Yapılan değişiklikler sonucunda, ilişkinin doğrudan veya dolaylı olarak ortaklık kanalıyla oluştuğu durumların örtülü kazanç dağıtımı kapsamında değerlendirilmesi için, en az \%10 oranında ortaklık, oy veya kar payı hakkının olması şartı aranacaktır. Herhangi bir ortaklık ilişkisi olmadan, doğrudan veya dolaylı olarak en az \%10 oranında oy veya kâr payı hakkının olduğu durumlarda da taraflar, ilişkili kişi olarak kabul edilecektir. İlişkili kişiler açısından bu oranlar toplu olarak dikkate alınacaktır. İlişkili kişi kavramının genişletilerek, sermaye ve kar payı oranı konusundaki belirsizliğin giderilmesiyle, uygulamanın biraz daha netlik kazanacağını söylemek doğru olacaktır.

Ayrıca, 6728 Sayılı Kanun ile 5520 Sayılı Kurumlar Vergisi Kanunu'nun mevcut 8. fikrasında da değişikliğe gidilerek, Bakanlar Kurulu'na ikinci fıkrada yer alan ilişkili kişi ile ilgili oranları; gerçek kişiler, kurumlar, doğrudan veya dolaylı ortaklar itibarıyla ya da ortaklık payının edinim şekline göre topluca veya ayrı ayrı olmak üzere \%1'e kadar indirme ya da \%25'e kadar çıkarma ve oran şartını kaldırma yetkisi verilmiştir.

\subsection{Gelir Vergisi Kanunu'na Göre İlişkili Kişi ve İşlemler}

Transfer fiyatlandırması yoluyla örtülü kazanç dağıtımı konusu, kurumlar vergisi mükelleflerini olduğu kadar gelir vergisi mükelleflerini de bağlamaktadır. Bu kapsamda, 01.01.2007 tarihinden itibaren geçerli olmak üzere, 28.03.2007 tarihinde kabul edilen, 04.04.2007 Tarih ve 26483 Sayılı Resmi Gazete'de yayımlanarak yürürlüğe giren, 5615 Sayılı Gelir Vergisi Kanunu ve Bazı Kanunlarda Değişiklik Yapılmasına Dair Kanun'un 3. maddesi ile, 193 Sayılı Gelir Vergisi Kanunu'nun 41.maddesi yeniden tesis edilmiştir. Buna göre, 193 Sayılı Gelir Vergisi Kanunu'nun 41. maddesinin birinci fıkrasına 4 numaralı bentten sonra gelmek üzere, aşağıdaki 5 numaralı bent eklenmiştir (Yıldız, 2017,30-31):

"Bu fikranın 1 ilâ 4 numaralı bentlerinde yazılı olan işlemler hariç olmak üzere, teşebbüs sahibinin, ilişkili kişilerle emsallere uygunluk ilkesine aykırı olarak tespit edilen bedel veya fiyatlar üzerinden mal veya hizmet alım ya da satıminda bulunması halinde, emsallere uygun bedel veya fiyatlar ile teşebbüs sahibince uygulanmış bedel veya fiyat arasındaki işletme aleyhine oluşan farklar işletmeden çekilmişs sayılır. 
Transfer

Fiyatlandırması

Yoluyla Örtülü

Kazanç

Dağıtımında İlişkil

Kişi Kavramının

6728 Sayılı Kanun

Kapsaminda

Değerlendirilmesi

28

Teşebbüs sahibinin eşi, üstsoy ve altsoyu, üçüncü derece dahil yansoy ve kayın hısımları ile doğrudan veya dolaylı ortağı bulunduğu şirketler, bu şirketlerin ortaklar, bu şirketlerin idaresi, denetimi veya sermayesi bakımından kontrolü altında bulunan diğer şirketler ilişkili kişi sayılır.

Bu bent uygulamasinda, imalat ve inşaat, kiralama ve kiraya verme, ödünç para alınmasi veya verilmesi, ücret, ikramiye ve benzeri ödemeleri gerektiren işlemler, her hâl ve şartta mal veya hizmet alım ya da satımı olarak değerlendirilir.

İşletmeden çekilmiş sayılan farklar, ilişkili kişi tarafindan beyan edilmiş gelir veya kurumlar vergisi matrahının hesabında dikkate alınmış ise ilişkili kişinin vergilendirme işlemleri buna göre düzeltilir. İlişkili kişiler ve bu kişilerle yapılan işlemler hakkında bu maddede yer almayan hususlar bakımından, 5520 sayıl Kurumlar Vergisi Kanununun 13 üncü maddesi hükmü uygulanır."

Böylelikle, 5615 Sayılı Kanun'un 3. Maddesiyle eklenen 5. bent hükmü ile 5520 Sayılı Kurumlar Vergisi Kanunu'nda yer alan transfer fiyatlandırması yoluyla örtülü kazanç dağıtımı uygulamasına paralel bir düzenleme getirilmiştir. Bu bağlamda, Kanun maddesinden hareketle, "teşebbüs sahibi" terimi ise, ticari kazanç ya da zirai kazanç yönünden, gelir vergisine tabi gerçek kişiler ile adi ortaklıkların ortakları, kollektif şirketlerin ortakları, adi ve eshamlı komandit şirketlerin komandite ortaklarını ifade etmektedir (GİB, 2010,3; 1 Nolu Tebliğ, 2007, Consulta, 3). Bir gerçek kişi açısından “ilişkili kişi”ler ise, GVK'nın 41/5. maddesinde;

- Teşebbüs sahibinin eşi, üstsoy ve altsoyu, üçüncü derece dahil yansoy ve kayın hisımları,

- Doğrudan veya dolaylı ortağı bulunduğu şirketler,

- Doğrudan veya dolaylı ortağı bulunduğu şirketlerin ortakları,

- Doğrudan veya dolaylı ortağı bulunduğu şirketlerin idaresi, denetimi veya sermayesi bakımından kontrolü altında bulunan diğer şirketler olarak sıralanmaktadır.

1 Seri Nolu Tebliğ dikkate alındığında; Gelir Vergisi Kanunu kapsamında, transfer fiyatlandırması yoluyla örtülü kazanç dağıtımı uygulamasının ilişkili kişiler kapsamına, Gelir Vergisi Kanunu'nun uygulamasında teşebbüs sahibinin eşi, üstsoy ve altsoyu, üçüncü derece dahil yansoy ve kayın hısımları ile doğrudan veya dolaylı ortağ bulunduğu şirketler, bu şirketlerin ortakları, bu şirketlerin idaresi, denetimi veya sermayesi bakımından nüfuzu altında bulunan diğer şirketler girmektedir. 
Teşebbüs sahibi, bir şirkete doğrudan veya dolaylı ortak ise, teşebbüs sahibi ile söz konusu şirketler, transfer fiyatlandırması yoluyla örtülü kazanç dağıtımına konu olan ilişkili kişi kabul edilmektedir. Bu ilişkide, sermaye veya kâr payı oranının herhangi bir önemi bulunmamaktadır. Örneğin, şahsi işletmesi olan (A) gerçek kişisinin aynı zamanda $(\mathrm{ABC})$ Ltd.Şti.'nde ortaklığı bulunması durumunda, (A) gerçek kişisi ile (ABC) Ltd.Şti. ilişkili kişi kapsamında değerlendirilecektir. Aynı şekilde teşebbüs sahibi bir şirkete doğrudan veya dolaylı ortak ise teşebbüs sahibi ile söz konusu şirketin ortakları ilişkili kişi kapsamındadır. Örneğin; (A) gerçek kişisi ile $(\mathrm{ABC})$ Ltd.Şti.'nin diğer ortağı olan (B) gerçek kişisi ilişkili kişi kapsamındadır.

Teşebbüs sahibinin doğrudan veya dolaylı ortağı bulunduğu şirketlerin idaresi, denetimi veya sermayesi bakımından kontrolü altında bulunan diğer şirketler ifadesinden, teşebbüs sahibinin doğrudan veya dolaylı olarak bağlı bulunduğu şirket/şirketlerin ekonomik ve ticari kararlarını etkileyebilecek ölçüde sermayesine, kâr payına veya oy kullanma hakkına sahip olduğu diğer şirketler anlaşılmaktadır. Diğer taraftan, teşebbüs sahibinin eşi, üstsoy ve altsoyu, üçüncü derece dâhil yansoy ve kayın hısımları, doğrudan veya dolaylı ortağı bulunduğu şirketler ile bu şirketlerin ortakları, bu şirketlerin idaresi, denetimi veya sermayesi bakımından kontrolü altında bulunan diğer şirketlerin aralarındaki ilişki, Gelir Vergisi Kanunu'nun uygulamasında ilişkili kişi kapsaminda değerlendirilecektir.

Söz konusu madde doğrultusunda, gelir vergisi mükellefleri bakımından, transfer fiyatlandırması yoluyla örtülü kazancın doğması için, işletme sahibinin, ilişkili kişiler ile emsallere uygunluk ilkesine aykırı olarak tespit edilen fiyat ya da değer üzerinden mal veya hizmet alış ya da satışında bulunması gerekecektir. Bu madde kapsamında, imalat ve inşaat, kiralama ve kiraya verme, ödünç para alınması ya da verilmesi, ücret, ikramiye ve benzeri ödemeleri gerektiren işlemler mal ya da hizmet alımı ya da satımı olarak dikkate alınacaktır.

Ayrıca Tebliğ'e göre, teşebbüs sahibi ile ilişkili kişiler arasındaki işlemlerin yine, emsallere uygun bedel veya fiyatlar ile işletme sahibi tarafından uygulanmış emsale aykırı bedel veya fiyat arasındaki işletme aleyhine oluşan farkların işletmeden çekileceği hüküm altına alınmıştır. İşletmeden çekilecek bu farkların, ilişkili kişi tarafından beyan edilmiş gelir ya da kurumlar vergisi matrahının hesaplanmasında dikkate alınmış olması halinde, ilişkili kişinin vergilendirme işlemlerinin buna göre düzeltileceği ifade edilmiştir. Örneğin, (ABC) Adi Ortaklığı'nın ortaklarından (A)'nın ortağı olduğu (D) Ltd. Şti. ile emsallere uygunluk 
Transfer

Fiyatlandırması

Yoluyla Örtülü

Kazanç

Dağıtımında İlişkil

Kişi Kavramının

6728 Sayılı Kanun

Kapsaminda

Değerlendirilmesi

30 ilkesine aykırı olarak tespit edilen fiyat üzerinden yaptığı mal satışı işlemi ilişkili kişilerle yapılmış sayılarak emsallere uygun bedel ile teşebbüs sahibince uygulanmış bedel arasındaki işletme aleyhine oluşan farklar işletmeden çekilmiş sayılacaktır.

İster kurumlar vergisi isterse gelir vergisi mükellefleri yönünden olsun, kazancın elde edildiği ülke vergi sisteminin, Türk vergi sisteminin vergilendirme kapasitesi ile aynı düzeyde bir vergilendirme imkanı sağlayıp sağlamadığı ve bilgi değişimi hususunun göz önünde bulundurulması suretiyle Bakanlar Kurulu'nca ilan edilecek ülkelerde veya bölgelerde bulunan kişilerle yapılmış tüm işlemler, ilişkili kişilerle yapılmış olarak kabul edilecektir (Tekin, Kartaloğlu, 2007, 95; Consulta,2017, 2; Erol, 2013, 38-39). Diğer taraftan, aralarında ortaklık ilişkisi bulunup bulunmadığına bakılmaksızın, yurt dişında bulunan bir kurum ile Türkiye'de dağıtıcı (distribütör) olarak faaliyette bulunan kurum, ilişkili kişi kapsamında ele alınacaktır. Zira, bir gerçek kişi/kurum ile bir başka gerçek kişi/kurum arasında, olağan ticari faaliyet çerçevesinde, sadece bayilik ilişkisinin bulunması halinde, söz konusu gerçek kişi ya da kurumlar, bayiliğe ilişkin mal ve hizmetler bakımından ilişkili kişi kapsamına dahil edilmeyecektir (GİB, 2010,4).

Gerek 5520 Sayılı KVK md.13'de gerekse 193 Sayılı Gelir Vergisi Kanunu md. 41/5'de, transfer fiyatlandırması yoluyla örtülü kazanç dağıtımıyla ilgili olarak; ilişkili kişi, emsallere uygunluk ilkesi, kurumların, ilişkili kişilerle yaptığı işlemlerde uygulayacağı fiyat veya bedelleri belirlemede kullanacağı yöntemler, mükellefin talebi üzerine Maliye Bakanlığı ile yapılabilecek anlaşmalar ve düzeltme işlemleri hakkında ayrıntılı düzenlemelere yer verildiği görülmektedir. Bu kapsamda yapılan düzenlemelerin amac1, ilişkili kişilerle mal ya da hizmet alış veya satış faaliyetinde bulunan gerçek kişi ve kurumların gelirlerinin tam ve doğru olarak tespitini sağlamak, transfer fiyatlandırması yoluyla vergi matrahının gerçeğe aykırı olarak beyan edilmesine engel olmaktır (GİB, 2010,2).

\section{SONUÇ VE ÖNERİLER}

Çalışmamızda, 5520 Sayılı Kurumlar Vergisi Kanunu kapsamında yapılmış bir düzenleme olup, esasen çok önemli olan transfer fiyatlandırması yoluyla örtülü kazanç dağıtımı konusu irdelenmiştir.

5520 Sayılı Kanun'un “transfer fiyatlandırması yoluyla örtülü kazanç dağıtımı" başlıklı 13. maddesinde yer alan ilişkili kişi kavramıyla ilgili olarak kanunlaştığ 2006 yılından 2016 yılına kadarki 10 yıllık dönemde bir değişiklik yapılmamıştır. Bu yönüyle ilk değişiklik, 15.07.2016 tarihinde kabul edilen, 09.08.2016 Tarih ve 29796 Sayılı Resmi Gazete'de 
yayımlanarak yürürlüğe giren 6728 Sayılı Yatırım Ortamının İyileştirilmesi Amacıyla Bazı Kanunlarda Değişiklik Yapılmasına Dair Kanun'un 59. maddesi ile yapılmıştır.

6728 Sayılı Kanun ile yapılan değişiklikle, ilişkinin doğrudan veya dolaylı olarak ortaklık kanalıyla oluştuğu durumların, transfer fiyatlandırması yoluyla örtülü kazanç dağıtımı kapsamında sayılabilmesi için en az \%10 oranında ortaklık, oy veya kâr payı hakkının olması şartı getirilmiştir. Diğer taraftan, ortaklık ilişkisi olmadan doğrudan veya dolaylı olarak en az \%10 oranında oy veya kâr payı hakkının olduğu durumlarda da, tarafların ilişkili kişi sayılacağı yönünde düzenleme yapılmıştır. İlişkili kişiler açısından bu oranlar topluca dikkate alınabilecektir. Ayrıca Bakanlar Kurulu, söz konusu oranları, gerçek kişiler, kurumlar, doğrudan veya dolaylı ortaklar itibariyle ya da ortaklık payının edinim şekline göre, topluca veya ayrı ayrı \%1'e kadar indirmeye ya da \%25'e kadar çıkarmaya ya da oran şartını kaldırmaya yetkili kılınmıştır.

İlişkili kişi kavramına ilişkin olarak yapılan bu düzenlemenin içeriğiyle benzer yöndeki önerilerin akademik çalışmalarda da ifade edildiği görülmüştür.

Çalışmada, ilişkili kişi kavramının transfer fiyatlandırması yoluyla örtülü kazanç dağıtımı konusundaki önemi açıklanmaya çalışılmıştır. Bundan sonra yapılacak çalışmalar için, 6728 Sayılı Kanun ile yapılan düzenlemenin, transfer fiyatlandırması yoluyla örtülü kazanç dağıtımında ilişkili kişi kavramının netleştirilmesi ve sınırlarının belirlenmesi açısından fayda sağlayacağı düşünülmektedir.

\section{KAYNAKÇA}

193 Sayılı Gelir Vergisi Kanunu. (1960).

5520 Sayılı Kurumlar Vergisi Kanunu. (2006).

5615 Sayılı Gelir Vergisi Kanunu ve Bazı Kanunlarda Değişiklik Yapılmasına Dair Kanun. (2007).

6728 Sayılı Yatırım Ortamının İyileştirilmesi Amacıyla Bazı Kanunlarda Değişiklik Yapılmasına Dair Kanun. ( 09.08.2016 Tarihli 29796 Sayılı Resmi Gazete).

Ağar, S. (2011). Transfer Fiyatlandırması Yoluyla Örtülü Kazanç Dağıtımında "İlişkili Kişi”, TBB Dergisi, 94.

Ağar, S. (2011). Transfer Fiyatlandırması-Örtülü Kazanç Dağıtımı, Ankara.

Akdoğan, İ. (2007). 5520 Sayılı Kurumlar Vergisi Kanununda Yer Alan Vergi Güvenlik Müesseseleri Örtülü Sermaye ve Transfer Fiyatlandırması Yoluyla Örtülü Kazanç Dağıtımı, Vergi Dünyası Dergisi, 34. 
Transfer

Fiyatlandırması

Yoluyla Örtülü

Kazanç

Dağıtımında İlişkil

Kişi Kavramının

6728 Sayılı Kanun

Kapsaminda

Değerlendirilmesi

32

Borokowsji, S.C. (1997). Ex Ante en Ex Post Discration Over Arm's Lenght Tranfer Pricing, The International Journal of Accounting.

Bulut, N. (2012) Örtülü Sermaye ve Transfer Fiyatlandırması Yoluyla Örtülü Kazanç Dağıtımı Müessesesinde Düzeltme İşlemleri ve Değerlendirilmesi, Vergi

Dünyası Dergisi, 367.

Casey, M. P. (1985). International Transfer Pricing, Management Accounting.

Consulta. (2017). Transfer Fiyatlandırması, Transfer Fiyatlandırması Raporu, Transfer Fiyatlandırması Yoluyla Örtülü Kazanç Dağıtımı, http://consulta.com.tr/icerik/transfer-fiyatlandirmasi-ortulu-sermaye/65 (08.02.2017).

Çakır, İ. (2009). Transfer Fiyatlandırması ve Vergilemede Etkinlik, Dokuz Eylül Üniversitesi Sosyal Bilimler Enstitüsü Maliye Anabilim Dalı, Yüksek Lisans Tezi.

Ece, N. (2016). Transfer Fiyatlandırmada OECD Yaklaşımı Açısından Geleneksel İşlem Yöntemi ve Uygulama Örnekleri, İSMMMO Mali Çözüm Dergisi.

Elitaş, C. Elitaş, B.L. ve ÖZKAL, E.S. (2009). Transfer Fiyatlaması ve Kullanılan Yöntemler Arasında Karşılaştırmalı Bir Uygulama, İSMMMO Mali Çözüm Dergisi, 91.

Erhan, D.U. (2012). Kar Maksimizasyonu Açısından Transfer Fiyatlandırması Uygulamalarında Ekonomik Analiz İhtiyacı, Muhasebe ve Denetime Bakıs Dergisi.

Erol, N. (2013). Kurumlar Vergisinde Transfer Fiyatlandırması Yoluyla Örtülü Kazanç Dağıtımı, Okan Üniversitesi Sosyal Bilimler Enstitüsü İşletme Anabilim Dalı, Yüksek Lisans Tezi.

Gelir İdaresi Başkanlığı. (2010). Transfer Fiyatlandırması Yoluyla Örtülü Kazanç Dağıtımı Hakkında Rehber, Yayın No: 114.

Güler, İ. (2006). Transfer Fiyatlandırması Yoluyla Örtülü Kazanç Dağıtımı, https://www.muhasebenet.net/makale_ibrahim_guler_transfer\%20fiyatlandi rmasi\%20yoluyla\%20ortulu\%20kazanc\%20dagitimi.html (17.01.2017).

Gümüş, E. (2007). Transfer Fiyatlandırması Yoluyla Örtülü Kazanç Dağıtımında Peşin Fiyatlandırma Anlaşmaları, Vergi Dünyası Dergisi, 313.

Güney, S. Bozkurt, R. (2010). Transfer Fiyatlandırmanın Türkiye'deki İşletmelerde Uygulanamamasının Nedenleri, 9. Ulusal İşletmecilik Kongresi, 6-8 Mayıs 2010, Zonguldak.

Heitger, L. E. Matulich, S. (1980). Managerial Accounting, Mc Graw Hill, Inc., New York.

Horngren, T.C. Foster, G. ve Datar, S. (1972). Cost Accounting An Managerial Emphasis, Printice Hall, USA. 
Işık, H. (2005). Çok Uluslu Şirketlerde Örtülü Kazanç ve Örtülü Sermaye Uluslararası Düzenlemeler ve Uygulamalar İle Türk Vergi Sisteminin Karşılaştırılması Ve Öneriler, Maliye Bakanlı̆̆ı Araştırma Planlama ve Koordinasyon Kurulu Başkanlığı, Yayın No: 2005/370.

Transfer Fiyatlandırması Yoluyla Örtülü

Kazanç

MALIYY BAKANLIĞI. (18.11.2007 Tarihli 26704 Sayılı Resmi Gazete). 1 Seri Nolu Transfer Fiyatlandırması Yoluyla Örtülü Kazanç Dağıtımı Hakkında Genel Tebliğ.

MALIYY BAKANLIĞI. (22.04.2008 Tarihli 26855 Sayılı Resmi Gazete). 2 Seri Nolu Transfer Fiyatlandırması Yoluyla Örtülü Kazanç Dağıtımı Hakkında Genel Tebliği.

Mısırlıŏlu, İ.U. (2003). Bölümler Arası Transfer Fiyatlaması Ve Bir Uygulama, ISMMMO Mali Çözüm Dergisi, 62.

Pazarçeviren, S. (1987). Transfer Fiyat Sistemi ve Transfer Fiyatlarının Doğrusal Programlama Metodu Kullanılarak Belirlenmesi, İstanbul Üniversitesi Sosyal Bilimler Enstitüsü İşletme Anabilim Dalı, Doktora Tezi.

Saraçoğlu, F. Kaya, E. (2006). Yeni Kurumlar Vergisi Kanunu ve Transfer Fiyatlandırması Yoluyla Örtülü Kazanç Dağıtımı, Vergi Sorunları Dergisi, 216.

Soydan Yaltı, B. (1995). Uluslararası Vergi Anlaşmaları, Beta Yayınları.

Tekin, C. Kartaloğlu, E. (2007). Örtülü Sermaye ve Transfer Fiyatlandırması Yoluyla Örtülü Kazanç Dağıtımında Dönem Sonu İşlemleri, İSMMMO Yayınları-96, Mart Matbaacılık, İstanbul.

TMSK. (2005). İlişkili Taraf Açıklamalarına İlişkin Türkiye Muhasebe Standardı (TMS-24) Hakkında 17 Sıra Nolu Tebliğ, 31.12.2005 Tarihli 26040 Sayılı Resmi Gazete.

Yıldız, A.M. (2017). 2016 Yılı Gelir Vergisi Beyanname Düzenleme Rehberi, Sakarya SMMMO Yayını, Başak Matbaacılık Ltd.Şti., Ankara.

Yiğit Şakar, A. (2008). Transfer Fiyatlandırması Yoluyla Örtülü Kazanç Dağıtımı, Sicil Dergisi, 3:9. 